\title{
Las lenguas de signos deberían ser una asignatura obligatoria en el currículum escolar, como un idioma más
}

\section{Sign languages should be a compulsory subject in the school curriculum, like any other language}

\section{Marisol BENITO REY}

Departamento de Lingüística, Universidad Autónoma de Madrid marisol.benito@uam.es

\section{INTRODUCCIÓN}

Dada mi condición de CODA (Children of Deaf Adults), y como miembro de una familia con personas sordas (con padres, tíos sordos), he realizado tareas de intérprete y, en cierto modo, de mediadora cultural desde una corta edad. En ocasiones, esta labor ha sido abrumadora debido a la falta de madurez, así como a la dificultad de los temas a interpretar por tratarse de asuntos legales, administrativos, entre otros, puesto que siempre se comienza con esta labor desde edad temprana. Continuamente me he encontrado nadando entre dos culturas, la cultura sorda y la oyente, siendo la LSE parte de mi identidad cultural y personal.

Desde el año 2015 (año en el que fue realizada la entrevista) hasta nuestros días, la situación de las personas sordas en nuestro país no ha mejorado sustancialmente, muy al contrario, se ha visto agravada por la pandemia. En cierto modo, se han visto afectados los derechos de las personas con discapacidad (no solo de las personas 
sordas). Tal y como ha publicado en marzo del 2021 el Comité Español de Representantes de Personas con Discapacidad (CERMI), que denuncia en su informe el impacto negativo que ha supuesto la pandemia en los derechos de las personas con discapacidad.

Desde las instituciones se habla de siempre de inclusión y de atención a la diversidad, pero esta pandemia ha hecho que miles de personas sordas se vean más aisladas que antes de la COVID-19. No se ha realizado ningún tipo de adaptación ni se han tenido en cuenta sus problemas de accesibilidad. Esta pandemia ha puesto de manifiesto las carencias de las administraciones con respecto a políticas sociales, ahora más que nunca es necesario que las personas normoyentes aprendan la Lengua de Signos para poder comunicarse con personas sordas o sordociegas.

¿Cómo reaccionarían ustedes al conocer que una persona sorda no sabe que alguien le está dirigiendo la palabra porque no puede ver que su interlocutor mueve los labios? Esta cuestión es una realidad a la que muchas personas con discapacidad auditiva deben enfrentarse a diario. En una lengua en la que los componentes no manuales (la expresión facial, oralización...) son primordiales para captar el mensaje, la mascarilla supone una barrera en la comunicación, pero no solo para aquellas personas que se comunican mediante la lengua de signos, también, para aquellas personas que poseen algún grado de pérdida auditiva o, incluso, para personas con algún trastorno del espectro autista (TEA) y a las que el uso de las mascarillas les resta volumen, llegando, incluso, a apagar las voces dificultando su comprensión. Al aislamiento que sufrimos todos se suma el de las personas con discapacidad auditiva. Muchas personas sordas o con algún grado de pérdida auditiva necesitan apoyarse a la hora de comunicarse con su entorno en la lectura labial (aunque no todas personas sordas la empleen).

En febrero de 2021 el Ministerio de Consumo publicó una normativa por la cual, se establecen los requisitos que las mascarillas higiénicas transparente deben cumplir para poder ser homologadas. Sin embargo, hasta el momento, ninguna empresa ha realizado homologación alguna de este tipo de mascarillas, por lo que las personas sordas deben continuar aisladas. A esta dificultad añadida de las mascarillas se suma la reducción de los servicios de interpretación y en algunos lugares, la prohibición acudir con intérprete a realizar gestiones burocráticas de tipo médico o administrativo, con una reducción del 90 \% de la atención presencial. Se hace necesario, más que nunca, un aumento de los servicios de intérpretes y mediadores.

Un año después del comienzo de la pandemia, la situación no ha mejorado para la Comunidad Sorda en nuestro país. Sin embargo, y para evitar en la medida de lo posible esa exclusión social, me gustaría terminar con la siguiente frase que resume una necesidad: «Las personas sordas no pueden aprender a oír, pero tú si puedes aprender lengua de signos».

Palabras clave: lengua de signos; CODA; interpretación.

Marisol BENITO REY

Las lenguas de signos deberían ser una asignatura obligatoria en el currículum escolar...
CLINA

vol. 7-1, June 2021, 129-138

elSSN: 2444-1961

Ediciones Universidad de Salamanca - CC BY-NC-ND 


\section{ENTREVISTA}

Fecha: 5/6/2015

Don de Lenguas: Buenas tardes. Hoy tenemos aquí a Marisol Benito Rey, doctora en Filología y profesora de la Universidad Autónoma de Madrid. Escribió su tesis doctoral, dato que nos parece especialmente interesante, sobre la lengua de signos. Cuéntanos un poco de qué trata esta tesis.

Marisol Benito Rey: Hola, buenas tardes. Mi tesis es un análisis comparativo entre la Lengua de Signos Española y la Lengua de Signos Alemana (Deutsche Gebärdensprache) desde diferentes perspectivas; no solamente desde el punto de vista lingüístico, sino también desde el punto de vista histórico.

DDL: ¿Y por qué la lengua de signos? Quiero decir, eres filóloga alemana, entiendo la comparación Alemania-España, pero ¿qué te ha acercado a la lengua de signos?

MBR: En realidad la razón principal es que yo soy CODA, soy hija de padres sordos.

DDL: Para los que no lo saben, CODA es la abreviatura del inglés «Children of Deaf Adults». Así se denominan a los hijos de padres sordos.

MBR: Efectivamente. Y, en cierto modo, la lengua de signos no deja de ser mi lengua materna, mi primera lengua, asimismo, yo fui la mayor de mis hermanas. Yo crecí en el seno de una familia sorda, con padres y tíos sordos por lo que la lengua que yo empleaba para comunicarme era la Lengua de Signos Española (LSE) y siempre he sentido la necesidad de ocuparme y estudiar esta lengua.

DDL: ¿Cuándo aprendiste la lengua oral? Quiero decir: ¿en tus primeros años de vida no hablabas, solo signabas?

MBR: Sí, los primeros años solamente signaba puesto que en casa no había nadie más que mis padres.

\section{DDL: ¿Abuelos?}

MBR: Claro, mis abuelos eran oyentes, pero no convivían con nosotros, venían de visita. Según algunos estudios, al carecer de una referencia de una persona oyente cercana que viva en la unidad familiar, se tarda en comenzar a emplear la lengua oral. La primera opción siempre es signar y se empieza a signar desde muy pequeño, con 6 u 8 meses ya se emplean algunos signos para poder comunicarse con los padres. La lengua oral se va adquiriendo en el entorno familiar (no sordo), escolar, con amigos, etc.

Marisol BENITO REY

Las lenguas de signos deberían ser una asignatura obligatoria en el currículum escolar... 
DDL: ¿Todavía te sientes más cómoda en la lengua de signos por ser tu lengua nativa, la primera lengua que aprendiste, o en la actualidad no notas ninguna diferencia y te consideras totalmente bilingüe?

MBR: Depende de en qué campo me es más fácil comunicarme o bien en la lengua oral o bien en la lengua de signos (LS). Normalmente, en el ámbito de los sentimientos me es más fácil expresarme mediante signos. En ocasiones, simplemente, me viene a la mente antes el signo que la palabra en lengua oral.

DDL: Porque es lo que primero aprendiste. Sí, claro, entiendo. Muy interesante. ¿Y cuáles son tus conclusiones? No quiero que me cuentes tu tesis, que eso desbordaría esta breve entrevista, pero yo creo que todavía hay muchas personas que incluso desconocen, que exista más de una lengua de signos en el mundo. Cada vez hay menos, pero el desconocimiento sobre las lenguas de signos aún es bastante elevado. Por ello, me parece interesante que nos cuentes algo sobre estas dos lenguas de signos ya que conoces ambas. Entonces, ¿qué diferencias hay? ¿Realmente son tan distintas?

MBR: En primer lugar, y una de las razones para llevar a cabo mi tesis y para investigar en este campo, era poder demostrar que se trata de lenguas propiamente dichas, por lo tanto, son lenguas naturales. Hay un número elevado de personas que piensa que son signos que se realizan al azar, hecho que no es cierto. Los signos dentro de las LS tienen una estructura concreta al igual que las palabras en la lengua oral española. La variación de alguno de los parámetros estructurales puede provocar que el mensaje no llegue al receptor.

En rasgos generales, las conclusiones serían, primero, que existen en el mundo alrededor de 144 LS diferentes, de familias lingüísticas distintas. Todas ellas poseen un denominador común, el canal viso-gestual lo que les confiere muchas similitudes. La mayor diferencia que yo he podido constatar a raíz de las investigaciones entre la Lengua de Signos Española y la Lengua de Signos Alemana (DGS) radica en el vocabulario, mientras la morfología y la sintaxis son muy similares, por otro lado, el vocabulario difiere en mayor medida, sobre todo cuando se trata de términos que no son transparentes o icónicos, que no reflejan la realidad.

DDL: ¿Se podría hacer una comparativa como con las lenguas orales de una misma familia lingüística?

MBR: Siempre pongo el ejemplo para mis alumnos en la asignatura de Lengua de Signos.

DDL: Un momento, un inciso. Marisol Benito Rey, además, ha impartido la asignatura Introducción al Lengua de Signos Española en la Universidad de Alcalá y actualmente en la Universidad Autónoma de Madrid.

Marisol BENITO REY

Las lenguas de signos deberían ser una asignatura obligatoria en el currículum escolar...
CLINA

vol. 7-1, June 2021, 129-138

elSSN: 2444-1961

Ediciones Universidad de Salamanca - CC BY-NC-ND 
MBR: Sí, como asignatura transversal. Como primer acercamiento al tema, realizo una clase en la que intento romper las falsas creencias que existen entorno a las LS y siempre surge la misma pregunta acerca de la existencia de una lengua de signos universal, no existe como tal, existe un Sistema de Signos Internacional, pero no una lengua en sí. Aprovecho para poner un ejemplo claro, existe la posibilidad de que personas que hablan LS distintas pueden comunicarse entre sí. Es como si español y un italiano (oyentes) se comunicasen, es decir, ellos se entenderían, sabrían de qué están hablando, el mensaje llegaría, pero no con todos los matices ni con todas las particularidades. En otras palabras, una persona signante que domine la LSE sería capaz de comunicarse con otra persona con discapacidad auditiva de otro país, a grandes rasgos.

DDL: También, hay que tener en cuenta la particularidad de las personas sordas que viven en un entorno oyente durante toda su vida y esta necesidad constante de hacerse entender por personas que no hablen su lengua nativa, que es la lengua de signos. Es mi idea. Por ello también tienen una capacidad mayor de entenderse con una persona sorda de otro país sin conocer la misma lengua puesto que están muy acostumbrados a hablar con «extranjeros».

MBR: Las personas sordas, en realidad, muchas veces se sienten extranjeros en su propio país, porque nadie les entiende. Es decir, ellos se ven obligados a esforzarse para ser entendidos y yo siempre he creído que las lenguas de signos deberían ser una asignatura obligatoria en el currículum escolar, como un idioma más ya sea inglés, francés, alemán o italiano, puesto que son hablantes del propio país y la única forma de poder integrarlos es que el resto conozca su lengua.

DDL: Porque claro, una persona sorda no se puede volver oyente, pero un oyente puede aprender lengua de signos y esa es la idea de la inclusión.

MBR: Ahí está, efectivamente. Lo acabas de describir perfectamente.

DDL: Ahora quiero llegar al contenido de tu ponencia del simposio por el que estamos reunidos actualmente aquí en Salamanca, el V Simposio sobre la Traducción y la Interpretación del Alemán. En ella te centras en la interpretación de la lengua de signos y hablas sobre algunas particularidades de esta especialidad. ¿Es cierto?

MBR: Yo me centro en dos problemas que surgen a la hora de interpretar, no de una lengua de signos a una lengua oral (o viceversa), sino de una lengua de signos a otra lengua signos.

DDL: Los intérpretes sordos.

MBR: U oyentes que conocen varias lenguas de signos. Este tema está poco estudiado por lo que nace, principalmente, a raíz de una experiencia propia. Dado mi

Marisol BENITO REY

Las lenguas de signos deberían ser una asignatura obligatoria en el currículum escolar...
CLINA

vol. 7-1, June 2021, 129-138

elSSN: 2444-1961

Ediciones Universidad de Salamanca - CC BY-NC-ND 
conocimiento acerca de la LSE y de la DGS pude constatar que estas particularidades, que hasta ahora solo se habían tratado en el contexto de las lenguas orales, también eran susceptibles de ser estudiadas en las LS. Me refiero a los pares mínimos y a los falsos amigos que se dan, habitualmente, en las LO. Además de tratarse de un tema novedoso, era una forma de demostrar que las LS son lenguas, en sí mismas, puesto que observamos los mismos fenómenos que en las LO. Es decir, palabras que se realizan de forma similar en varias LS pueden tener significados diferentes que pueden llevar a equívoco.

DDL: Muy interesante. ¿Existe una formación de intérprete entre distintas lenguas de signos?

MBR: Que yo conozca, no.

DDL: Yo sé que existe una formación profesional de la Universidad de Hamburgo, pero enfocado en intérpretes sordos.

MBR: En este caso, no se trata de una LS a otra, sino de una LS al Sistema de Signos Internacional (SSI).

DDL: Claro, igual nos puedes explicar brevemente qué es el SSI.

MBR: Sí. El Sistema de Signos Internacional es un lenguaje, puesto que no se trata de una lengua natural, es un lenguaje artificial. Dicho sistema se creó en los años 90 como lengua franca como intento para que las personas sordas, independientemente del país de origen, pudieran comunicarse entre sí. Como sistema artificial no existe ningún hablante nativo de dicho sistema.

DDL: ¿Para ti cuál es la diferencia entre el lenguaje y lengua? ¿La lengua es como un idioma, alemán, francés?

MBR: Para mí, una lengua es algo natural que nace con la persona, es un sistema de signos o códigos que posee una determinada comunidad lingüística, mientras que el lenguaje es la facultad humana de comunicarse mediante signos escritos u orales. Hay expertos lingüistas que se refieren a las LS con el término Lenguaje de Signos, pero desde el mismo momento en el que la Comunidad Sorda defiende que se trata de la LS de signos, creo que ya no hay discusión posible.

DDL: Entonces, te interrumpí. El SSI es un código que se creó, una lengua universal, ¿para qué fin?

Marisol BENITO REY

Las lenguas de signos deberían ser una asignatura obligatoria en el currículum escolar... 
MBR: Se creó con la idea de que funcionase como lengua vehicular, un poco como el inglés. Todo el mundo conoce en mayor o menor medida el inglés y puede comunicarse sin conocer la lengua del país en el que se encuentre.

DDL: ¿Como el esperanto, que no cuajó? La idea es la misma.

MBR: Aparte del esperanto, hubo algún intento más que tampoco cuajó como el Gestuno. Este SSI sí ha arraigado, pero presenta un problema ya que es desconocido para el $90 \%$ de la población sorda que emplea la LS.

DDL: Ahí hace falta una labor de difusión por enseñanza.

MBR: O de concienciación. Yo creo que muchos no conocen su existencia, hablo, sobre todo, de personas sordas a partir de 60 años, porque no lo han necesitado.

DDL: Y acceso a los medios, como Internet ya cambia todo.

MBR: Sí, incluso las personas mayores ya tienen acceso a Internet, WhatsApp, a las Redes Sociales. Pero este Sistema de Signos Internacional se usa sobre todo en concentraciones internacionales de la Federación Mundial de Sordos (WFD) o concentraciones culturales o deportivas a nivel internacional o a nivel europeo.

DDL: Porque vemos que las personas sordas están muy organizadas, incluso a nivel internacional.

MBR: Luchan por sus derechos y porque se reconozca a las LS como lenguas oficiales, hecho que tampoco hasta el momento sucede en todos los países.

DDL: ¿En España la LS no está reconocida como lengua oficial?

MBR: No, la lengua de signos no es lengua oficial, sino que está reconocida oficialmente por el Estado. No tiene estatus de lengua oficial del Estado, porque si fuera así, sería obligatorio que hubiera un intérprete en todas las administraciones y no es el caso. Lo que supondría una adaptación de todas las Instituciones.

DDL: Nadie lo quiere pagar. ¿Pero no se creó una ley específica en el año 2008?

MBR: Sí, en el 2007, la Ley 27/2007.

DDL: Perdón. Que reconoce oficialmente a la LS y que se comprometió a realizar ciertos cambios en ese ámbito.

Marisol BENITO REY Las lenguas de signos deberían ser una asignatura obligatoria en el currículum escolar... 
MBR: Claro. Dicha Ley reconoce y regula la LSE como lengua de las personas sordas, con discapacidad auditiva y sordociegas y supuso un gran avance a la hora de visibilizar al colectivo sordo y a la LS. A raíz de esa Ley se propuso la creación del Centro de Normalización Lingüística, CNLSE, donde trabajan por la normalización de la LSE, velando por su buen uso y contribuyendo a garantizar los derechos lingüísticos de las personas signantes, aunque aún quede mucho camino por recorrer.

DDL: No sé si nos puedes decir algo sobre la formación del intérprete en LSE en España. Porque aquí en esta Facultad de lenguas, de Traducción e Interpretación no existe la LS.

MBR: ¿Ni como lengua C?

DDL: No. Se pueden cursar en el centro de idiomas unos cursos de LSE, pero es independiente de cualquier formación de cualquier grado o máster. Si uno de nuestros oyentes está interesado en aprender esta especialidad, la de la interpretación de la lengua de signos española, ¿cómo lo puede hacer?

MBR: A nivel universitario es muy difícil. Desde el curso 2008-2009 existe en la Universidad Pompeu Fabra la posibilidad de estudiar Grado de Traducción e Interpretación con perfil de interpretación/traducción de Lengua de Signos Catalana. En otras universidades se pueden cursar estudios de Máster como en la Universidad de Vigo. Si no se quiere estudiar en la universidad se puede acudir a la Confederación Nacional de Sordos de España (CNSE) donde se oferta un Ciclo Formativo de Grado Superior en Mediación Comunicativa. Además, siempre se pueden dirigir a las asociaciones de sordos donde se imparten cursos de LS.

DDL: ¿Y un título oficial de LSE, no existe?

MBR: Existe, de reciente creación. Las LS se rigen por los mismos principios y recomendaciones que propone el Marco Europeo de Referencia de las Lenguas, como una lengua más y con los mismos niveles (A1, A2 ...).

DDL: Y sobre la Pompeu Fabra, creo que hay que añadir que está en Cataluña y que no se trata de la lengua de signos española, porque eso también igual es un dato que se desconoce. En España oficialmente existen dos lenguas de signos.

MBR: Sí. Existen oficialmente la LSE y la Lengua de Signos Catalana (LSC). Me gustaría aclarar que dentro de cada una de las lenguas existen variedades dialectales. En principio, como lenguas reconocidas de manera oficial por el Estado hablaríamos solo estas dos.

DDL: ¿Tú dirías que hablas y entiendes las dos? ¿Son muy distintas?

Marisol BENITO REY

Las lenguas de signos deberían ser una asignatura obligatoria en el currículum escolar...
CLINA

vol. 7-1, June 2021, 129-138

elSSN: 2444-1961

Ediciones Universidad de Salamanca - CC BY-NC-ND 
MBR: Yo hablo la LSE, pero entiendo la LSC. He coincidido con personas signantes de varias comunidades y las diferencias que puedan existir se reduce, principalmente, a términos concretos que no impiden en ningún momento la comunicación.

DDL: No sé si vuelvo mucho para atrás. En tu tesis, me has dicho antes de esta entrevista, que estuviste investigando en Alemania, estuviste ahí físicamente. ¿lgual nos puedes brevemente decir cómo está la situación de la formación en Alemania? ¿Allí hay a nivel universitario más que aquí, o no? ¿Cómo está la situación?

MBR: En Alemania la ley que reconoce oficialmente la Lengua de Signos Alemana (DGS) se aprobó en el año 2002, es decir, cinco años antes que en nuestro país. La situación en realidad de la DGS es similar, dentro de la Administración varía muy poco. Quizás en ámbitos concretos el empleo de la DGS es mayor, se trabaja más por la inclusión de las personas sordas. La disponibilidad de intérpretes de LS, así como la interpretación y subtitulado en los medios de comunicación es superior. Allí existe la opción de estudiar lo que se conoce como Deaf Studies, en varias universidades, Hamburg Universität, Humboldt-Universität zu Berlin, Universität zu Köln (entre otras). En estas universidades disponen de institutos y facultades completas dedicadas por entero a estos estudios que tienen que ver con la LS y con la cultura sorda. En ese sentido sí que están más concienciados con la necesidad de que la lengua de signos merece tener un grado propio y que las personas sordas pertenecen a una cultura concreta, que es la cultura sorda.

DDL: ¿Y esto no sería como tener una Facultad independiente de alemán, por ejemplo, en vez de tener una Facultad de interpretación de inglés, francés...? Quiero decir, el instituto en Alemania, si lo entiendo bien es, solo de lengua de signos y dices que esto es positivo.

MBR: Creo que es positivo porque es una forma de reconocer que las LS no son simples instrumentos de comunicación para las personas sordas, sino que, de este modo, se les otorga un estatus de lengua, convirtiéndolas en objeto de ciencia. No simplemente se aprende como una asignatura optativa o una asignatura transversal más, sino que queda patente que se trata de lenguas complejas que necesita ser estudiadas en 3 o 4 años para conseguir los conocimientos lingüísticos y culturales.

\section{Entrevista: «Don de Lenguas»}

Transcripción: Beatriz Guerrero García

Enlace: https://www.ivoox.com/entrevista-a-marisol-benito-06-05-15-audios-mp3_rf_24583960_1.html Duración: 21:17:00

Marisol BENITO REY

Las lenguas de signos deberían ser una asignatura obligatoria en el currículum escolar...
CLINA

vol. 7-1, June 2021, 129-138

eISSN: 2444-1961

Ediciones Universidad de Salamanca - CC BY-NC-ND 


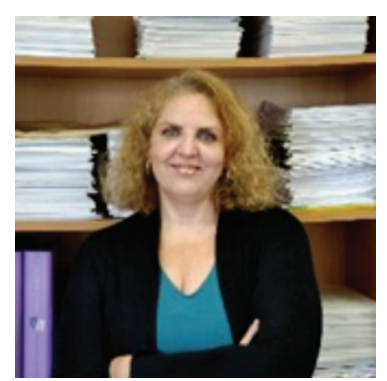

Doctora en Filología Moderna por la UAH y, en la actualidad, profesora del Departamento de Lingüística General, Lenguas Modernas, Lógica y F. ${ }^{a}$ de la Ciencia, T. ${ }^{a}$ de la Literatura y Literatura Comparada y Estudios de Asia Oriental de la UAM. Realicó estudios de Germanística en la Universidad Complutense de Madrid y en la Ruhr-Universität Bochum, donde cursó, además, un Postgrado de Enseñanza de Alemán como Lengua Extranjera. Ha realizado estancias de investigación en el Institut für Deutschegebärdensprache de la Universität Hamburg. Es coordinadora del SEDIP (Seminarios Didácticos Permanentes) del Colegio Oficial de Doctores y Licenciados en Filosofía y Letras y en Ciencias de la Comunidad de Madrid desde el año 2004. Publica e investiga sobre las lenguas de signos (LS), diversidad funcional, análisis del discurso y lingüística aplicada. Es integrante del grupo de investigación Wor(l)ds lab de la UAM y subdirectora del Máster "Máster en Humanidades Digitales para un mundo sostenible».
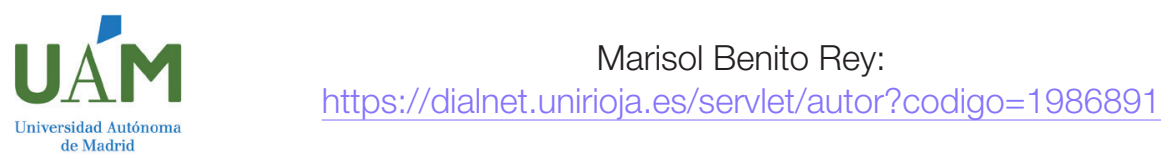

Marisol Benito Rey:

de Madrid

\section{BIBLIOGRAFÍA}

Ambadiang, Théophile., Benito, Marisol. y Canalda, Núria. (2021). Modalidad lingüística y formación de palabras: el caso de los procesos derivativos en las Lenguas de Signos Alemana (DGS), Catalana (LSC) y Española (LSE) en comparación con la lengua china (en prensa).

Benito Rey, Marisol. Aprendizaje de las personas con discapacidad auditiva en tiempos de pandemia, Peter Lang (en prensa).

Benito Rey, Marisol. 2016. La lectura labio-facial (LLF) en la investigación de procesos judiciales. Tonos Digital, N. ${ }^{\circ}$ 30, 2016. http://hdl. handle.net/10201/47883

Benito Rey, Marisol. 2015. Dos fenómenos que dificultan la interpretación en las lenguas de signos. En: Interacciones: reflexiones en torno a la Traducción e Interpretación del/al alemán.

Benito Rey, Marisol. 2007. Intentar superar clichés a través de estaciones de aprendizaje. Der Fremdsprachliche Unterricht Spanisch. 10-17.

Bascoy Lamelas, Montserrat; Benito Rey, Marisol. 2014. Aplicación práctica del aprendizaje colaborativo en la clase de alemán con fines específicos. En: 2340-3012. Disponible en línea en https://repositorio.uam.es/handle/10486/679647.

Benito Rey, Marisol. 2007. Intentar superar clichés a través de estaciones de aprendizaje. En: Der fremdsprachliche Unterricht Spanisch. 10-17.

Benito Rey, Marisol. 2014.Estudio contrastivo de la LSE y la DGS desde diferentes perspectivas.

Disponible en línea en https://www.cnlse.es/sites/default/files/estudiocontrastivo.pdf

Benito Rey, Marisol. 2012. Análisis comparativo de las lenguas de signos española y alemana.

Disponible en línea en https://dialnet.unirioja.es/servlet/tesis?codigo=179090.

Marisol BENITO REY

Las lenguas de signos deberían ser una asignatura obligatoria en el currículum escolar...
CLINA

vol. 7-1, June 2021, 129-138

elSSN: 2444-1961

Ediciones Universidad de Salamanca - CC BY-NC-ND 